\title{
PENSANDO COM AS FLORESTAS: UMA EXPOSIÇÃO DE QUESTÕES DO ANTROPOMORFISMO À LUZ DAS PALAVRAS DO XAMÃ DAVI KOPENAWA
}

\author{
THINKING WITH THE FORESTS: AN \\ EXPOSURE OF ANTHROPOMORPHISM \\ QUESTIONS ENLIGHTENED BY THE \\ WORDS OF SHAMAN DAVI KOPENAWA
}

\author{
Pedro Paulo Valerio Vaz \\ pedroovalerio@gmail.com \\ Graduado em Direito pela Universidade de Brasília. Mestrando em Antropologia pela Universidade Federal \\ de Minas Gerais. \\ Orcid: https://orcid.org/0000-0001-9617-8580
}

\section{RESUMO}

Este artigo tem o objetivo de fazer uma reflexão junto às palavras do xamã yanomami Davi Kopenawa, contidas na obra A queda do céu. O texto em questão foi construído mediante o trabalho conjunto do antropólogo francês Bruce Albert e o xamã yanomami Davi Kopenawa. Esta pesquisa busca cooperar na exposição das consequências que esse trabalho "a quatro mãos" vem causando à teoria antropológica, principalmente aquela ligada ao xamanismo. A frase de Davi Kopenawa "a floresta é inteligente, ela tem um pensamento" será o centro de irradiação deste artigo, e se buscará friccioná-la com diferentes textos antropológicos contemporâneos, para que caminhos e desvios surjam e para que as faíscas desses encontros sejam expostas.

Palavras-chave: Xamanismo. Antropomorfismo. Florestas.

\begin{abstract}
This article aims to engage a reflection regarding the words of the yanomami shaman, Davi Kopenawa, contained in the book The falling sky. The book in question was a result of a joint work between the French anthropologist Bruce Albert and the yanomami Shaman Davi Kopenawa, and this research seeks to cooperate in exposing the consequences that this "four hands" work has been causing to anthropological theory, and especially to the anthropological theory linked to shamanism. David Kopenawa sentence "the forest is intelligent, it has a thought" will be the point of dissemination of this article, and we will try to friction this sentence with different contemporary anthropological texts so that paths and deviations arise, and sparks are exposed.
\end{abstract}

Keywords: Shamanism. Anthropomorphism. Forests. 


\section{INTRODUÇÃO}

O que fazer com o texto $A$ queda do céu, construído em uma parceria entre o xamã Davi Kopenawa e o antropólogo Bruce Albert? Ou melhor, o que os antropólogos podem fazer com as palavras do xamã yanõmami tëpëë? Essa ainda é uma pergunta muito nova ${ }^{2}$, à qual este artigo busca trazer alguma cooperação. A presente pesquisa tem como principal intenção explorar as palavras, os insights, do xamã Davi Kopenawa, escritas na obra $A$ queda do céu, e junto às palavras do xamã, mas não menos importante, expor também questões ligadas ao antropomorfismo da teoria antropológica nape $\ddot{e}^{3}$. Resumidamente, o que se tenta fazer aqui é friccionar o texto xamânico com outros textos ocidentais, de forma que surjam caminhos em comum, desvios, ou mesmo para que seja possível descrever as faíscas do atrito desses encontros. Busco menos fazer os textos ocidentais convergirem para as afirmações de Kopenawa, e mais expor as divergências entre os vários autores que serão apresentados, pensando os possíveis efeitos, tremores e tensões que as afirmações xamânicas implicam à tradição moderna antropológica escrita.

O centro de irradiação dos problemas deste artigo é a simples frase: "A floresta é inteligente, ela tem um pensamento" (KOPENAWA; ALBERT, 2016, p. 497). Porém, isso não significa que este artigo irá começar por essa frase do xamã, ou mesmo que irá se manter sempre próximo a esse centro. $\mathrm{O}$ artigo, aliás, desenvolve-se primeiramente a partir de considerações sobre as bases teóricas da modernidade, que servem para situar o momento histórico no qual a frase do xamã aparece. Feito isso, iremos a pontos da teoria antropológica sobre o xamanismo, problematizando-os para, após esse percurso, chegar diretamente às palavras de Kopenawa.

As palavras do xamã são diferentes. Elas vêm de muito longe e falam de coisas desconhecidas pelas pessoas comuns [...]. Se quisermos conseguir essas palavras de sabedoria, temos que responder aos espíritos [...] estudando sob a orientação de nossos xamãs mais velhos não temos a menor necessidade de olhar para as folhas de papel. [...] Nós somos habitantes da floresta, nosso estudo é outro (KOPENAWA; ALBERT, 2016, p. 458, 460-461).

A floresta, junto ao seu pensamento e ao seu lado espiritual, foi encarada desde cedo pela antropologia em meio às questões da antropomorfia ${ }^{4}$, ou seja, se a floresta pensa, ela deve pensar como o humano, ela deve ter algo de humano. Dentro dessa problemática, imagina-se uma floresta que pensa, sobretudo, por intermédio de características humanas. Somando-se a isso, vê-se também a afirmação de que "uma floresta pensa" enquanto um erro de cálculo dos povos indígenas, que confundem partes que na verdade são separadas, a humanidade e a natureza.

$\mathrm{O}$ animismo enquanto conceito de uma certa tradição antropológica se alicerça na ideia básica de que existe animação, pensamento, agência ${ }^{5}$, para além dos humanos, e, assim, contém dentro de si as questões sobre o antropomorfismo (BENSUSAN, 2017, p. 11). E o conceito vem sendo repensado atualmente por influentes escritores, como os antropólogos Philippe Descola, Eduardo Viveiros de Castro e Eduardo Kohn, e também por filósofos brasileiros, como Hilan Bensusan e Marco Valentim ${ }^{6}$. Esses autores deram um novo fôlego à problemática que o conceito envolve e trouxeram-no de novo para o centro dos debates antropológicos. Para situar as discussões sobre o antropomorfismo neste artigo, acompanharemos as relações de concordância e discordância entre esses diferentes arranjos teóricos. Os autores citados conversam entre si em seus próprios textos, o que tanto facilita quanto torna a sua análise conjunta mais potente. 
Afinal, pensa o moderno convicto: por que levar em conta que uma floresta pensa? Por que especular que/com uma floresta pensa? Isso não seria assunto de contos de fadas ou crenças de um passado longínquo? Enquanto primeira provocação, a resposta mais simples e direta a essas questões é: devemos levar em conta que as florestas pensam, justamente porque elas pensam (KOHN, 2013, p. 22). Os espíritos sabem disso, Kopenawa (2016) sabe disso, outros xamãs também sabem disso, outros vários povos também sabem disso, e de acordo com as previsões do xamã yanomami (KOPENAWA; ALBERT, 2016, p. 508), logo o branco será obrigada a saber disso.

Para Albert (2016), o xamã realiza uma "contra-antropologia histórica do mundo branco, a partir da comparação de esferas culturais que, em suas viagens, ele percebera como pontos de embate cruciais entre o seu mundo e o nosso" (KOPENAWA; ALBERT, 2016, p. 542). A estratégia de escrita desenvolvida neste artigo se desenvolve apoiada em uma diferença marcante entre os Yanomami e os napë, "forasteiros, inimigos" (KOPENAWA; ALBERT, 2016, p. 610). Ou seja, há de um lado o povo da floresta (índios, xamãs, outros), e do outro os brancos (ocidentais, cidades, modernos).

Para realizar essa posição, a aposta deste artigo começa por tratar o xamanismo como algo prioritário, sobretudo, de forma que suas prioridades sejam tratadas enquanto prioritárias. $\mathrm{O}$ artigo busca caminhar mais próximo dos espíritos, dos xamãs, da magia, das bruxas, da yãkoana e do tempo dos sonhos do que dos estados-nações, do cristianismo e do direito-constituição. Trataremos tratar o mundo moderno como uma parte do mundo xamânico, uma parte que hoje se mostra grande e destruidora, mas nem por isso deixa de ser apenas uma parte (VIVEIROS DE CASTRO, 2015b).

Este artigo se apoia, então, na inspiração de um ataque reverso à tradição ocidental, uma espécie de desconstrução reversa (HOLBRAAD; PEDERSEN, 2017, p. 294). Reverso, pois as intervenções traçadas neste artigo partem de caminhos apontados pelo xamã Davi Kopenawa. Então, são intervenções de fora para dentro, do mundo do xamã para o mundo dos napë. Como indica o conceito "contra-antropologia" de Albert (2016), grande parte do discurso de Kopenawa (2016) se dá seguindo uma estratégia de uma comparação de culturas/mundos, que parte de um mundo a priori xamânico, para então realizar uma comparação com o mundo napë.

Assim, a intenção não é a de impor ao texto do xamã Kopenawa uma ideia já predeterminada e fixa sobre o assunto, as convicções de algum sistema ocidental sobre o que pode ser uma floresta que pensa. Partiremos de uma circunscrição do que significa uma floresta para os modernos, mas apenas para que o contraste deixe ver melhor o que realmente importa aqui, que é como a floresta se constitui nos próprios termos do xamã. Buscaremos, nas palavras de Kopenawa, a organização e a composição da floresta, para repensar o que ela é ou quem ela é. Em suma, o que acontece quando o xamanismo empurra os argumentos dos antropólogos para lugares ainda desconhecidos? Ou, o que acontece quando as palavras do xamã incidem nos argumentos dos antropólogos, de modo a gerar efeitos sobre esses argumentos? (VIVEIROS DE CASTRO, 2002, p. 115).

\section{QUEM É O MODERNO? AS BASES TEÓRICAS DA MODERNIDADE}

A exposição das bases teóricas fundamentais da modernidade tem como objetivo, nos planos deste artigo, possibilitar que se veja além dela. 
Tentaremos colocar nos termos mais simples o que é a modernidade, para que se torne possível perceber o que está para além do moderno. Neste artigo não se busca pensar essas bases enquanto a única verdade, sequer busca-se confirmá-las ou reforçá-las. Pelo contrário, a intenção é de revirar e torcer essas bases para que se vislumbre coisas novas, para que coisas diferentes apareçam e possam ser vistas.

A constituição teológica-política moderna neste artigo é definida como aquela que busca construir uma fronteira entre os humanos e a natureza, entre o futuro e o passado, uma fronteira que separa completa e irreversivelmente esses dois polos (BENSUSAN, 2017, p. 35). Um esforço de bifurcação entre o cosmos/universo/natureza e os humanos/cultura/pensamento marca a constituição moderna. Em suma, a modernidade é uma ruptura (LATOUR, 2013, p. 15). A origem da palavra modernus se encontra no século $\mathrm{V}$, sendo utilizada para marcar a separação entre uma nova Roma cristã, que estava então surgindo, e a antiga Roma pagã, que estava sendo ultrapassada (HABERMAS, 2001, p. 169). O que há em comum entre as definições da modernidade, que são muitas, é que todas se referem a uma passagem no tempo, a uma ruptura, que de um lado deixa aqueles que perderam a disputa, que são os antigos, o passado, a natureza, e do outro lado coloca aqueles que venceram, os humanos, o novo, o futuro (LATOUR, 2013, p. 15).

A maioria dos modos de agir e pensar do ocidente apresentam uma separação entre os humanos (política) e a natureza (ontologia) (BENSUSAN, 2017, p. 35). O lado dos humanos é o campo do quem, enquanto o lado da natureza é o campo do quê. De um lado está a política, o pensamento, a humanidade, a cultura, o sujeito, a subjetividade, o interior, a alma, o eu, todos aqueles que podem conhecer, o campo do quem. Do outro lado está todo o resto, aquilo que apenas pode ser conhecido, a ontologia, o não-humano, o objeto, a natureza, $o$ ambiente, o campo do quê. Um em primeiro plano, o outro em segundo. Um protagonista, o outro coadjuvante. Conhecer é um ato de mão única nesse paradigma, sempre partindo do sujeito para o objeto, ou, do humano para a natureza (BENSUSAN, 2017, p. 39).

No entanto, nas últimas décadas, a desconfiança sobre esses modos de pensar e agir modernos, que separam perfeitamente o time dos humanos e o time da natureza, vem aumentando exponencialmente. Pois, enquanto as teorias mais comuns da modernidade buscam uma imagem de uma natureza enquanto coadjuvante, enquanto em um passivo segundo plano, o que se vê com a presente crise ambiental planetária é que todo o "resto" que foi colado do lado natural não se encaixa mais nas idealizações modernas (BENSUSAN, 2017, p. 41). A natureza não é mais um pano de fundo, sempre ali equilibrada e serena, por onde os humanos desfilam sua superioridade, pois subitamente ela se tornou raivosa e descontrolada (STENGERS, 2015, p. 46), assim assumindo o protagonismo da situação. E também, essa natureza que se revolta apresenta já muitas marcas causadas pelos humanos, e a separação entre os polos, que um dia já foi tão clara, vem se mostrando confusa.

A ideia do "Antropoceno"7 vem ganhando relevância na comunidade científica nos últimos anos, e ela marca o início de uma nova era geológica na qual a destruição humana descontrolada sobre a natureza tem um impacto decisivo. Essa nova era geológica aponta que a separação, o afastamento entre a natureza e os humanos já não é tão clara como um dia já, pois o humano se transformou em uma espécie de força geológica (CHAKRABARTY, 2013, p. 17), e assim o horizonte humano vem perdendo sua definição. O cheiro de plástico no ar atmosférico já é forte demais, para que a separação entre a natureza e os humanos seja uma imaginada como perfeita (BENSUSAN, 2017, p. 35). 


\section{A FLORESTA QUE PENSA}

"A floresta é inteligente, ela tem um pensamento" (KOPENAWA; ALBERT, 2016, p. 497), diz o xamã yanomami. Essa é uma afirmação que leva ao curto-circuito os dois lados separados inteiramente pelos principais e mais influentes modos de pensar/agir do ocidente. É uma afirmação que repente aproxima subitamente o humano do não-humano, tornando-os próximos demais, parecidos demais, causando assim um súbito mal-estar para a tradição ocidental. Ter a floresta como algo que pensa - então alguém e não mais algo - liga polos que no ocidente foram afastados para que a própria humanidade pudesse ser definida, pois neste caso separar é definir, e como já foi visto, é determinante para a tradição ocidental que a natureza não pense, não tenha agência. Nós humanos - somos aqueles que pensam, têm alma, interior, agência, e, então, definimo-nos em contraste com aquilo que não pensa.

A afirmação xamânica incide diretamente no limite traçado pela tradição moderna para definir o nós (humanos), incide no limite do anthropos, e assim, ataca o limite no qual os modernos se apoiam para reconhecer os humanos (BENSUSAN, 2017, p. 18). O limite parece não ter valor para o xamã, ou mesmo não existir. Se não existe limite, então o pensamento está espalhado por todos os cantos, e o nós (humano) alcança muito mais que os humanos, levando-se a imaginar que o pensamento pode alcançar tudo o que existe. Assim, estamos diante de uma cosmopolítica (STENGERS, 2005, p. 995), uma política cósmica (VIVEIROS DE CASTRO, 1996, p. 120), de forma que tudo aquilo que se acreditava estar para fora do limite político, ou seja, a natureza, apresenta-se enquanto um ou vários agentes políticos que acenam para além dos humanos. Sendo assim, longe de ser uma exclusividade dos humanos, a política é disseminada em tudo e todos.

O pampsiquismo enquanto intuição/insight que alicerça as palavras xamânicas, que a frase citada expressa, traz à tona um universo onde tudo pensa, onde qualquer coisa é um quem, onde o todo são todos, onde tudo é política (VIVEIROS DE CASTRO, 2015b). E o que o xamã quer dizer, quando diz que tudo é político/todos são políticos, não é o mesmo que um jovem que mora em algum centro de uma grande cidade quer dizer quando diz o mesmo. Não é difícil ouvir, da boca de uma pessoa da cidade, que "tudo é política", no sentido de que qualquer conversa entre dois humanos já é um ato político, um comportamento político. Nesse aspecto, fazer política é basicamente a comunicação entre dois pontos de vistas distintos (humanos), que defendem seu respectivo lado, seus próprios argumentos, na busca de convencer o outro a mudar de ideia, ou de chegar a um acordo em que ambos abram mão de algo para alcançar um ponto intermediário.

"Para nós, a política é outra coisa. São as palavras de Omama e dos xapiri que ele nos deixou" (KOPENAWA; ALBERT, 2016, p. 37). Para o xamã, tudo é político porque até o que não é humano, ou está para além do humano, faz política. Tudo é política justamente porque a política não está só entre os humanos. Os humanos, assim, são como atravessados por políticas exteriores. A política dos humanos está dentro de um cenário maior, o que torna os humanos apenas uma das partes dos seres potencialmente políticos. A constatação de que tudo é político do xamanismo leva a modernidade a uma intensificação expansiva paradoxal de sua restritiva base política (humana), o que faz a máquina que cria os humanos na modernidade desviar para um limite impossível, no qual nada mais seria excluído.

No recente livro Linhas de animismo futuro, o filósofo Hilan Bensusan (2017) explora diferentes autores, inclusive da antropologia, que vêm repensando o animismo e seus possíveis desenvolvimentos futuros. A afirmação 
pampsiquista de Kopenawa (2016) pode ser vista como responsável por gerar um efeito de dilatação do nós (humanos)para as doutrinas da modernidade (BENSUSAN, 2017, p. 18), argumenta o filósofo. O nós, então, englobaria não só os humanos, mas a floresta, englobando também o que não é humano. Isso abre a possibilidade de se pensar em uma politização de tudo, de pensar direitos para tudo o que há, e não apenas em direitos humanos. O gesto xamânico espalha o protagonismo político por toda parte, e pode ser visto como um condutor da dilatação sucessiva das esferas do nós, como se espalhasse vários protagonistas políticos para além do humano, indicando assim outra possibilidade de distribuição da agência.

O movimento proposto por Bensusan (2017) abre espaço para que o limite que separa os humanos do resto seja deslocado, movido para diferentes pontos. E a partir do momento que se pensa um aumento do raio político, é-se levado a pensar até onde essas esferas podem ser dilatadas. Ainda na obra de Bensusan (2017), no primeiro capítulo denominado Animismo, Ancião Ciborgue, tem-se os rascunhos de uma possível política animista. A questão é que a divisão moderna entre os humanos e a natureza se dá primeiramente com a criação de um nós ainda mais restrito e limitado que todos os humanos, um nós (humano) dentro do nós (humano), formado pelos humanos verdadeiros, os homens, brancos, ricos, adultos, héteros e cissexuais (BENSUSAN, 2017, p. 18), que continuam sendo a essência do humano ocidental nos dias de hoje. E então, quando se diz que existe agência, ou política, ou direito, para além deste restrito círculo, já se tem uma semente de uma política animista. No entanto, o gesto animista é realmente alcançado quando a agência é levada para além das fronteiras dos humanos (BENSUSAN, 2017, p. 18).

As esferas dilatantes do animismo podem ser vistas como se estivessem realizando o movimento de tornar capacitado para fazer política tudo aquilo que não era (BENSUSAN, 2017, p. 53). Começam, assim, por um movimento para além do homem branco que vai em direção às minorias entre os humanos, que são os "imigrantes, negros, índios, mulheres, população trans, crianças, loucos, doentes" (BENSUSAN, 2017, p. 53). Depois, seguem para os não-humanos, "o alimento, o animal, a paisagem, as populações vegetais, os ecossistemas, a biodiversidade, a terra" (BENSUSAN, 2017, p. 53).

Esse modo de analisar o efeito que o animismo causa na modernidade tem a força de implodir a divisão entre os humanos e o resto, e não apenas conservá-la. Permite, assim, questionar a opção que mantém que apenas alguns seres sejam "o lócus exclusivo de toda política" (BENSUSAN, 2017, p. 53). O movimento animista causa uma implosão nas fronteiras ocidentais permitindo, de relance, observar o íngreme penhasco que se abre.

Ou seja, um mundo com capacidades conceituais, propósitos, agencias, alianças políticas ou senso de importância, ainda que não sejam as capacidades conceituais, propósitos, agências, alianças políticas ou senso de importância humanos. Os animistas invocam a possibilidade de uma animação não humana, e isso é o que provoca muito desconforto, já que invocar a possibilidade não é apenas uma outra animação, é também uma animação dos outros (BENSUSAN, 2017, p. 23).

Se aquilo que não pensava agora pensa, talvez ele não pense exatamente igual àquilo que pensava sozinho antes. Ou seja, pensar em outros pensamentos implica também pensar o pensamento dos outros. O que é importante destes argumentos é provocar o leitor para uma interpretação do animismo que não seja uma simples projeção do humano por tudo. Descobrir algo novo, para depois dizer que já se sabia o que estava lá, ou então dizer que as novas políticas são políticas humanas, não é o fim da linha. Pois o movimento de dilatação, 
conforme vai se intensificando, torna a política cada vez mais estranha ao se imaginar o seu movimento gradativo de expansão. Por exemplo, imaginar uma expansão da política para os macacos parece fácil, para todos os mamíferos ainda continua parecendo fácil. No entanto, para formas mais simples de vida, como os vírus, a expansão da política começa a se mostrar atordoante, e ao se pensar nas pedras, por exemplo, a situação se torna difícil de compreender. Ao que parece, quanto mais se dilata a fronteira, mais o movimento nos inclina a imaginar uma política estranha o suficiente para conseguir vislumbrar uma política não humana, uma política dos outros (BENSUSAN, 2017, p. 19).

\section{OS LIMITES DO ANTROPOMORFISMO; ANIMISMO E PERSPECTIVISMO}

Então, chegamos no ponto das discussões do antropomorfismo dentro da Antropologia. Há tempos os índios são considerados povos próximos ao antropomorfismo, mas de um modo caricatural e simples, em uma visão que os compara a crianças, que ainda não sabem diferenciar os objetos dos sujeitos (MORRISON, 2014, p. 38). A cosmologia apresentada por Kopenawa (2016) será neste artigo o principal instrumento para negar esse preconceito, sempre lida junto aos antropólogos que já discutiram o tema. O antropomorfismo vulgar/moderno, ou seja, a simples projeção, baseia-se na concepção do Ocidente do que é o humano. Mas, para o xamanismo, a questão se mostra outra, e o que pensamos ser o humano não é a mesma coisa que eles pensam ser o humano, pois, "uma das características que os tornam 'outros' consiste, precisamente no fato de que seus conceitos de 'humanos' são outros" (DANOWSKI; VIVEIROS DE CASTRO, 2014, p. 90). A questão é mais complexa que uma simples projeção do humano sobre a natureza, como se vislumbra nas palavras de Bensusan (2017), e como também mostrarão as palavras de Kopenawa.

\footnotetext{
Daí o modelo que desenvolvi de um sujeito transcendental — mais uma vez, é uma ficção totalmente eurocêntrica, mas pouco importa - que vai detectar ou não continuidades ou descontinuidades entre si, como sujeito dotado de um aparelho de deteç̧ão, cognitivo, simples, e o que ele observa à sua volta. E isso ele pode fazer graças a duas ferramentas principais que denominei 'interioridade' e 'fisicalidade' (DESCOLA, 2013b, p. 6).
}

Descola (2013a) foi talvez o maior responsável por guiar a palavra animismo para novos caminhos e dar mais fôlego às discussões que envolvem o termo na atualidade. O livro Beyond nature and culture é o ponto inicial da teoria antropológica animista contemporânea, uma nova fase do conceito antropológico, que passa a não mais ser visto enquanto um erro de cálculo dos povos antigos, também não enquanto uma patologia, mas enquanto uma alternativa ontológica de povos que ainda hoje são animistas. Para Descola (2013a), existem quatro tipos de ontologias, pois, dentro do modelo desenvolvido pelo antropólogo, são possíveis quatro "systems of the properties of existing beings" (DESCOLA, 2013a, p. 67), que convivem juntas ainda nos dias de hoje. Para se formar esses quatro sistemas relacionais, basta uma combinação entre as opções: (1) contínuo ou descontínuo; e (2) interioridade ou fisicalidade. Como resultado das diferentes combinações, se apresentam quatro sistemas, a saber: o totemismo (continuidade de interioridade e fisicalidade), o animismo (continuidade de interioridade, e descontinuidade de fisicalidade), o analogismo (descontinuidade de interioridade e de fisicalidade) e o naturalismo (continuidade de fisicalidade e descontinuidade de interioridade). 
O animismo é uma das quatro ontologias possíveis, e a que mais interessa neste artigo. São várias as regiões do mundo por onde o animismo está espalhado, como na Amazônia, na América do Norte, e na Ásia (DESCOLA, 2013a, p. 22). O animismo é aquele no qual a relação com o não humano é de semelhança de interioridade e de distinção dos corpos. $\mathrm{O}$ animismo é o inverso completo do naturalismo (modernidade) para o autor, pois enquanto um vê fisicalidade (contínua) em tudo, o outro vê interioridade (contínua). Em suma; animismo é aquilo que proporciona um interior, uma subjetividade, um sujeito (eu), a todo o mundo físico. Sendo assim, qualquer relação com o mundo é uma relação também humana, e então a humanidade é uma condição universal (SÁ JUNIOR, 2014, p. 19). Na floresta animista do autor, por onde se olha, veem-se humanos. Eles estão por todos os lados, de forma que uma planta aparece para as outras plantas enquanto humana, assim como uma pedra vê um humano ao olhar para uma outra pedra. Se todos têm o mesmo interior, o que diferencia os seres é o corpo, que muitas vezes é visto como descartável, como trocável (DESCOLA, 2013a, p. 72)

Para Descola (2013a), os não-humanos são percebidos no animismo como fazendo parte de grupos diversos, mas que se assemelham aos grupos humanos. A diferença mais importante na floresta não é então entre humanos e animais, mas sim entre diferentes tipos de humanos (DESCOLA, 2013a, p. 72). Neste caso, a onça para o humano é percebida como fazendo parte de um grupo que se comporta como os humanos, ou seja, com uma interioridade, pois como já visto, a semelhança de interioridade é a chave do animismo. Então, é como se houvesse "contratos sociais" entre os animais, que dotados com interioridade podem agir como humanos nas relações em grupo.

A questão é que o animismo não viabiliza expulsar tudo o que não é humano para o lado da natureza, um lado inferior e aberto aos abusos dos humanos. Assim, também impede que a única relação possível com ela seja a de dominação, que parte de um diagnóstico de que a natureza é constituída enquanto uma falta, como se algo a faltasse para que fosse humana. Isso porque, nesse sentido, ser parte da natureza é não ter uma interioridade, é não ter algo. Uma "natureza social" requer uma espécie de cooperação, de conversa, de negociação entre os seres cósmicos. Se o não-humano é considerado mais como sujeito do que qualquer outra coisa, fica difícil expulsá-lo, expulsar a natureza, o natural, o objeto, tudo que não é humano, para o lado dominado eternamente pelas leis matemáticas (DESCOLA, 2006, p. 457).

Os não-humanos formam grupos sociais para o animismo de Descola (2013a), e assim não são questões do quê, mas, sim, do quem. Ou seja, é como se por trás de todo quê, precipitasse um quem na floresta encantada. Os não-humanos têm interioridade, então sentem fome, frio, conversam, discutem, gostam de beber, de fumar, basicamente se relacionam "socialmente" com os outros não-humanos (DESCOLA, 2006, p. 114). Então os animais se relacionam com os outros animais assim como os humanos se relacionam com outros humanos. Ou melhor, os animais parecem aos próprios animais o que os humanos parecem aos humanos. Mas como um não-humano vê um humano? Ou, como o não-humano do humano vê aquele que se "autodetermina" humano? Em suma: como o animal vê o humano? Para o animismo de Descola (2013a), o animal vê o humano como um humano, ou seja, assim como o humano o vê. É nesse ponto que acontece a diferença entre o perspectivismo de Tânia Stolze Lima e Eduardo Viveiros de Castro, e o animismo de Descola, pois aquele é um passo analítico além deste.

Se os salmões parecem aos salmões o que os humanos parecem aos humanos - e isto é o animismo - os salmões não parecem humanos 
aos humanos, nem os humanos aos salmões - e isto é o perspectivismo (VIVEIROS DE CASTRO, 2002, p. 371).

O fato de o humano não ser visto como humano pelo não-humano (salmão) pode parecer à primeira vista apenas um detalhe sem importância, mas é um desvio fértil que leva a múltiplas consequências, que Viveiros de Castro (2002) explora intensamente em seus argumentos. A reflexão de Viveiros de Castro, o passo analítico que o antropólogo dá para além do animismo, leva a humanidade de fundo pressuposta no sistema ontológico de Descola (2013a), a continuidade de interioridade, a humanidade pacificada que circula os humanos, a se inclinar, a se desequilibrar. Propõe, assim, uma humanidade mais instável, que se esconde, que recusa de todo jeito se fixar, e que junto com ela arrasta o mundo também para uma alta temperatura de transformações (VIVEIROS DE CASTRO, 2002, p. 379).

De acordo com o exemplo já clássico do mundo perspectivista, o que para a onça é cauim, para o humano é sangue. Também, o que para o humano é um buraco na terra, para a anta é uma luxuosa casa (VIVEIROS DE CASTRO, 2002, p. 379). Essas afirmações indicam que todos os seres veem o mundo "da mesma maneira" (VIVEIROS DE CASTRO, 2002, p. 378), e o que muda são os mundos que são vistos. Mas é exatamente esse pressuposto que a modernidade não apresenta, pois esta coloca a possibilidade de representações diferentes sobre o mesmo único mundo. É como se a realidade no perspectivismo fosse menos um código normativo do que uma jurisprudência (VIVEIROS DE CASTRO, 2015b, p. 46), ou seja, ela está sempre aberta a constantes transformações e adições em seu corpo, sempre sendo refeita e discutida de acordo com a adição de novos agentes possíveis, é uma realidade sempre em questão.

O xamã é exatamente aquele que pode ver como uma cultura o que para alguns é natureza, ver "um evento, como sendo, em verdade uma ação" (VIVEIROS DE CASTRO, 2002, p. 359), ou também é aquele que pode ver para qual sujeito o objeto aponta, dentro de uma "ontologia flutuante". O xamã se mantém no limite entre as diferentes perspectivas e tem o "papel de interlocutor ativo no diálogo transespecífico" (VALENTIM, 2018, p. 358) entre os diferentes personagens cósmicos. O xamã é aquele então que vai para os diferentes lados, para os diferentes pontos de vista, podendo sempre retornar para trazer as palavras desses outros mundos para os não-xamãs. $\mathrm{O}$ xamã enquanto coringa da política é aquele que se relaciona com tudo e todos, é uma figura do limite, que sempre está em um movimento incessante de tradução dos lados desse limite. E nesse encontro dos diferentes lados, o que se coloca em jogo é também a qual mundo pertence naquele momento o xamã, e estar no mundo dos outros pode ser muito perigoso.

Como Viveiros de Castro (2002) diz em alguns momentos de seu artigo, a sua intenção com o perspectivismo é a de contrastá-lo com o seu "oposto polar" (VIVEIROS DE CASTRO, 2002, p. 359), o pensamento moderno. Para o autor, existem dois pontos de vista político-cosmológicos possíveis, que são o ameríndio e o ocidental. Ser relativista (ocidental) é acreditar que os humanos têm o poder de "representar" sempre parcialmente a natureza (no singular). Já ser um perspectivista (ameríndio) é acreditar que humanos e não-humanos possuem uma "unidade representativa ou fenomenológica puramente pronominal, aplicada indiferentemente a uma diversidade real" (VIVEIROS DE CASTRO, 2002, p. 379), são então diversas "naturezas", e apenas uma "cultura". Mas a questão não se resume a isso, e pode-se ir mais longe, explorando as epistemes que Viveiros de Castro (2002) desenha para cada um dos lados.

O sujeito, na epistemologia ocidental, é aquele que conhece, e para que o conhecimento seja realizado, ocorre um processo de dessubjetivação, 
que deve se empenhar em retirar o sujeito do objeto que busca conhecer, por fim, separadamente, enquanto só um objeto. Ou seja, deve-se diferenciar aquilo que é intrínseco ao objeto daquele que é o sujeito que o conhece, através do próprio ato de conhecer. É como se o objeto a ser conhecido estivesse de alguma forma contaminado pelo olhar daquele que o descreve, e por trás de todo objeto existisse um sujeito inicialmente, que ao fim do processo deve sumir para restar apenas objeto. Esse manual é o da objetivação. Assim, o outro — o objeto - ao final do processo é visto com a forma de uma coisa, com a forma de um quê. A epistemologia ocidental manda reduzir o sujeito ao ponto que todo o mundo seja um quê, e não um quem (VIVEIROS DE CASTRO, 2002, p. 358).

Já o xamanismo é uma vontade contrária à episteme ocidental, não uma dessubjetivação, mas sim uma hipersubjetivização, ou uma pan-subjetivização. O xamã não busca isolar o objeto, ou seja, reduzir qualquer subjetividade a um mínimo, mas sim "visa a revelação de um máximo de intencionalidade" (VIVEIROS DE CASTRO, 2002, p. 359). O xamã busca "tomar o ponto de vista daquilo que deve ser conhecido" (VIVEIROS DE CASTRO, 2002, p. 358), e dessa forma transformar qualquer quê em quem. Aquilo que está sendo conhecido requer "ser entendido como outras pessoas" (VIVEIROS DE CASTRO, 2002, p. 360). Conhecer é uma espécie de reconhecimento que outros também conhecem, ou seja, o que está sendo conhecido sempre também conhece. $\mathrm{O}$ sujeito conhecedor cria outros sujeitos para conhecer, e o sucesso do processo está ligado diretamente a saber "personificar".

Do lado moderno então temos o antropocentrismo, que faz do humano uma espécie atravessada pela transcendência, marcado com a exclusividade, que o torna como o centro da natureza. Já o antropomorfismo (DANOWSKI; VIVEIROS DE CASTRO, 2014, p. 94) xamânico funciona em um regime inverso, de forma que tudo o que existe é tão "pessoal" quanto nós (humanos), e há então uma expansão da psique por todos os cantos, e o pampsiquismo é sua arma. O xamã tem uma espécie de generosidade psíquica com tudo, ou melhor, com todos. Se no antropocentrismo o humano tem que ser bem dividido do resto, de tudo, para então poder alcançar seu status exclusivo, no antropomorfismo tudo tem que virar todos para que o conhecimento seja desenvolvido, e assim é preciso estar ciente que tudo na verdade são todos, ou seja, que a floresta pensa.

Ao invés de um pensamento restrito a pouquíssimas coisas, construído por meio de um movimento de limitação, que então reserva ao humano um lugar especial e o diferencia de todo o resto. No xamanismo se tem um movimento de expansão pampsiquista, que afirma que vários outros seres pensam como os humanos. Ao invés da redução materialista ocidental que só pode aproximar os humanos do resto do mundo quando diz que eles também são, no fundo, feitos de natureza, de "pura matéria", o xamanismo realiza, por sua vez, a aproximação de outro modo, pois é a natureza, a matéria "morta", que pensa como os humanos (DANOWSKI; VIVEIROS DE CASTRO, 2014, p. 97).

"A floresta é inteligente, ela tem um pensamento igual ao nosso" (KOPENAWA; ALBERT, 2016, p. 497). Essa frase que já foi citada em sua primeira parte na introdução, agora sofre a adição das palavras "ao nosso", e assim o xamã soma informações importantes ao quebra-cabeça que este artigo tenta montar. A floresta não só tem um pensamento, mas tem um pensamento igual ao nosso, diz Kopenawa (2016). Diante dessa afirmação xamânica, o passo mais óbvio do pensamento moderno é ponderar: se a floresta pensa, logo ela pensa igual ao humano, pois só o humano pensa. Uma vez que "nós" para o Ocidente são os humanos, a questão é dar à natureza um pensamento idêntico ao humano, ou seja, bastando projetar aquilo que só o humano tem para o lado de fora, mas mantendo bem demarcada a divisão entre os humanos e a natureza. No entanto, a questão é mais complexa que uma simples projeção de 
pensamento, pois a primeira afirmação do xamã — a floresta pensa - coloca em xeque exatamente quem são os humanos, como já foi problematizado antes.

O nome do artigo de Viveiros de Castro (1996) que apresenta o perspectivismo de forma articulada pela primeira vez é Os pronomes cosmológicos e o perspectivismo ameríndio. E para se entender o perspectivismo é preciso também apreender a diferença entre os nomes próprios e os pronomes. Viveiros de Castro (1996) diz o seguinte:

Assim, as auto-referências de tipo 'gente' significam 'pessoa', não 'membro da espécie humana'; e elas são pronomes pessoais, registrando o ponto de vista do sujeito que está falando, e não nomes próprios. Dizer então que os animais e espíritos são gente é dizer que são pessoas; é atribuir aos não humanos as capacidades de intencionalidade consciente e de 'agência' que definem a posição de sujeito (VIVEIROS DE CASTRO, 1996, p. 126).

Como o antropólogo carioca explica, a palavra ameríndia que o moderno traduz como "ser humano", para os ameríndios não indica a humanidade "como espécie natural, mas a condição social da pessoa" (VIVEIROS DE CASTRO, 2002, p. 71). Sendo assim, em vez de tomar o nome "gente" para o nome de alguma etnia de forma exclusiva, revela-se um "a gente", que funciona de forma posicional. O "nós", então, refere-se a nós (humanos) que estamos na mesma posição. Mesmo que tenha "a gente", existem muitos outros "agente(s)", pensa o perspectivismo. E assim, ser um humano revela, acima de tudo, a capacidade de ser de um coletivo (BENSUSAN, 2017, p. 65). Para o perspectivismo, de cada ponto de vista "há sempre nós e eles, nós e os demais - e chama-se de humanos apenas aqueles que estão entre nós" (BENSUSAN, 2017, p. 65).

A máquina posicional ameríndia mais que produzir humanos, produz grupos, coletivos, posicionamentos, sejam eles humanos ou não-humanos (BENSUSAN, 2017, p. 65). A humanidade nesse cenário é sempre "relacional; sendo condição e não espécie ou essência” (VALENTIM, 2018, p. 192). Sendo assim, o que os modernos chamam de humano, em contraste com todo o resto natural, é apenas como uma das posições "pessoais" possíveis, que são muitas. A exclusividade que caracteriza o humano moderno se desmancha no cosmos. Para o xamanismo, de um lado tem-se o nós (humanos), e do outro lado também tem-se outros nós (humanos).

É de suma importância para a máquina posicional que a humanidade possa ser perdida de acordo com os diferentes cenários de relações entre os diferentes grupos. A humanidade nesse cenário pode ser perdida por meio da influência e da exigência de agentes cósmicos sobrenaturais. A questão é que, nessa máquina, quando algum lado está se tornando humano, o outro lado está deixando de ser, e vice-versa, em um movimento sempre aberto a se reverter (VALENTIM, 2018, p. 194). Para quem não é xamã, um dos perigos da floresta é o de ter a humanidade como que roubada por outro agente cósmico que se posicionou oportunamente. A influência dos outros seres do cosmos tem o poder de colocar em dúvida quem você é, ou melhor, colocar em dúvida se você é um humano naquele momento e, junto a essa imposição, pode colocar em xeque a que mundo você pertence.

É um equívoco acreditar que o que está em jogo na afirmação de que a floresta pensa é a possibilidade de um mundo onde os animais vivem como os humanos modernos, sob uma constituição de leis que os coloca em um estado de paz eterna, em que todos estão protegidos pelos direitos humanos e são iguais perante o estado. Afinal, a floresta não se parece com uma espécie de Disneylândia, onde os diferentes animais são todos amigos e igualmente humanos. Uma 
marca da humanidade ameríndia, dessa humanidade dos outros, é a instabilidade da posição humana (VIVEIROS DE CASTRO, 2002, p. 349), pois na floresta a humanidade parece sempre estar em questão, prestes a se mostrar outra coisa se olhada com mais atenção.

\title{
A FLORESTA XAMÂNICA
}

\begin{abstract}
Depois de tomar o poder alucinógeno de suas árvores, nós vemos. Fazemos os espíritos da floresta, os espíritos xamânicos, dançarem suas danças de apresentação. Vemos com nossos olhos. Depois de 'morrer' sob o poder do alucinógeno, vemos a 'imagem essencial' da floresta. Vemos o céu sobrenatural! (ALBERT, 2002, p. 249).
\end{abstract}

O xamã yanomami utiliza a palavra "floresta" constantemente em suas narrativas, e a tradução mais simples, e comumente utilizada pelos brancos para a palavra "floresta" que o xamã sempre utiliza, é o que os modernos chamam de "natureza". Porém esta tradução simples esconde um sério problema, pois o xamã expressa que, aquilo que os brancos chamam natureza, para os Yanomami pode ser dividido em duas palavras. Kopenawa diz que parte daquilo que os brancos chamam de "natureza" tem o nome na língua yanomami de Urihi a (KOPENAWA, ALBERT, 2016, p. 475), que é a parte visível a todos, seja para os índios não xamãs, ou mesmo para os brancos, e também para os xamãs. A "Urihi a, terra-floresta" (KOPENAWA; ALBERT, 2016, p. 475), é aquilo que se vê em um estado ordinário de percepção, sem a utilização da substância psicoativa yãkoana. E existe também a Urihinari (KOPENAWA; ALBERT, 2016, p. 475), que então só os xamãs podem ver, uma parte da floresta que é visível só para os xamãs, que é o "espirito da floresta". A Urihinari "são as inumeráveis imagens das árvores, e das folhas" (KOPENAWA; ALBERT, 2016, p. 475), e também dos animais, do vento, dos rios, da lua, em suma, são os espíritos de tudo que existe na floresta, que estão "circulando por toda a mata" (KOPENAWA; ALBERT, 2016, p. 475). É o sobrenatural.

O "céu sobrenatural" (ALBERT, 2002, p. 249) é acessado através do consumo da substância psicoativa yãkoana, que abre as portas para o "tempo dos sonhos" (KOPENAWA; ALBERT, 2016, p. 77), o tempo onde os espíritos aparecem para os xamãs, e conversam com eles. A yãkoana é inalada na forma de pó, que é produzido através de um processo de preparação, que envolve o aquecimento e a mistura de diversos tipos de plantas (KOPENAWA; ALBERT. 2016, p. 612). Porém, basicamente a yãkoana é produzida da "resina tirada da parte interna da casca arvore Virola Elongata" (KOPENAWA; ALBERT, 2016, p. 612), que contem alta concentração do alcaloide dimetiltriptamina (DMT), que apresenta efeitos parecidos com os da conhecida substância LSD (KOPENAWA; ALBERT, 2016, p. 612). Para se tornar um xamã, é um pré-requisito que grandes quantidades de yãkoana sejam inaladas por semanas.

Logo, para o xamã yanomami, o que os brancos dão o nome de "natureza" é apenas uma parte do que os xamãs podem conhecer, é a Uriria, porém existe uma outra parte, que é a Urihinari, que é visível apenas para os xamas já iniciados. E aliás, os espíritos que habitam a floresta são sua parte mais importante, uma parte que mantem a vitalidade, a fertilidade, e a temperatura habitável da floresta (KOPENAWA; ALBERT, 2016, p. 475). Então, traduzir a palavra "floresta" usada por Kopenawa, como "natureza", é perder a parte mais importante da floresta, que é a multidão de espíritos que que os brancos, e os índios não xamãs, não tem acesso. Os xapiri (espíritos) é que são "os verdadeiros donos da floresta, e não os humanos" (KOPENAWA; ALBERT, 2016, p. 475), e estes espíritos passam desapercebidos pelos brancos, que não foram 
treinados através do xamanismo para vê-los. Em suma, a floresta que os xamãs têm acesso tem algo para além daquilo que os brancos chamam de "natureza".

O que o xamã expõe sobre o "céu sobrenatural" (ALBERT, 2002, p. 249) vai contra a supervalorização comum dos modernos, da cultura sobre a natureza, onde então a cultura sempre aparece acima da natureza. O sobrenatural apresentado pelo xamã yanomami se passa como um terceiro termo, que não é a natureza e também não é a cultura, o que impede o passo analítico moderno que supervaloriza a cultura. Para o xamã, existe algo para além da noção de natureza, algo sobrenatural, e "essa 'sobrenatureza' está tão incontestavelmente acima da cultura quanto a própria natureza está abaixo dela" (LÉVI-STRAUSS, 2013, p. 353).

"A floresta é inteligente, ela tem um pensamento igual ao nosso. Por isso ela sabe se defender com seus xapiri e seus seres maléficos" (KOPENAWA; ALBERT, 2016, p.497). Kopenawa continua a somar informações à frase que vem servindo como guia deste artigo. Agora, o xamã adiciona novos personagens para que o pensamento da floresta seja compreendido. Os xapiri $\mathrm{e}$ os seres maléficos (në wãri pë) fazem parte do conjunto maior de seres supervisíveis/invisíveis (yai thë pë) (KOPENAWA; ALBERT, 2016, p. 616), e são personagens de difícil ou impossível representação dentro dos modos de pensar predominantes na modernidade, que buscam incessantemente separar perfeitamente os humanos do resto. Isso porque estes personagens dificilmente são classificados como pura humanidade ou como pura natureza, sendo assim ao mesmo tempo não-humanos e também estranhamente humanos. São seres nem inteiramente humanos, nem inteiramente animais (VALENTIM, 2018, p. 194), ou são seres "other-than-human and yet all-too-human" (KOHN, 2013, p. 5).

Outra informação de suma importância dada nessas novas palavras do xamã é que a floresta não está sozinha, mas em uma relação de cooperação com outros seres, que também são coletivos políticos. Essa soma de seres pensantes à floresta, trazida por Kopenawa (2016), abre espaço para se pensar não em uma floresta vazia ou mesmo no "meio do nada", mas sim em uma floresta permeada por relações de diferentes seres, uma floresta que se mostra inundada da presença de infinitos espíritos. O xamã diz:

Os xapiri, apesar de serem sem número, habitam todos no topo dos morros e das montanhas. É sua morada. Não pensem que a floresta é vazia. Embora os brancos não os vejam, vivem nelas multidões de espíritos, tanto quanto animais de caça [...] São as imagens de todos os seres que andam pelo solo, sobem pelos galhos, ou possuem asas [...] Os espíritos que vivem nela são muito mais numerosos do que os humanos e todos os demais habitantes da floresta os conhecem (KOPENAWA; ALBERT, 2016, p. 118).

Se é possível dizer que a obra $A$ queda do céu tem um personagem principal, este personagem está no plural, e são os xapiri. Os xapiri são infinitos (KOPENAWA; ALBERT, 2016, p. 622), e estão por todos os cantos da floresta e também do livro. A palavra xapiri é traduzida (KOPENAWA; ALBERT, 2016, p. 161) pelo próprio xamã como "espírito" para que os brancos o entendam. Também, a palavra xapiri se confunde com a palavra xamã na língua yanomami, pois xamã se diz xapiri thë pë (gente espírito), enquanto os índios não xamãs, as "pessoas comuns" (KOPENAWA; ALBERT, 2016, p. 615), são chamadas de kuapora thë pë "(literalmente 'gente que simplesmente existe')" (KOPENAWA; ALBERT, 2016, p. 615). Os xamãs são então aqueles mais próximos dos xapiri, que além de manter contato com eles em conversas diretas por exemplo (KOPENAWA; ALBERT, 2016, p. 492), também se confundem com eles, o que se mostra exposto na própria palavra que designa ambos. 
Os xapiri são como os espectros dos primeiros seres, dos ancestrais animais (yarori), mas que continuam ainda dispersos pela floresta. Os primeiros seres então não desapareceram, mas sim se tornaram xapiri. Na verdade, a parte interior desses seres se tornou os xapiri, enquanto a outra parte, o exterior, a pele, se tornou os animais de caça (yaropë) (KOPENAWA; ALBERT, p. 613). A palavra yarori vem de "yaro (animal de caça) seguido do sufixo - ri [...] que denota superlativo, monstruoso, ou de extrema intensidade" (KOPENAWA; ALBERT. 2016, p. 614), e se refere à primeira humanidade ${ }^{8}$, que era extremamente instável e sempre na inclinação de se tornar um animal. Era como uma forma humana em constante metamorfose, e que devido a constantes comportamentos extravagantes, se transformou parte em animal de caça, e outra parte em xapiri.

Os xapiri, por exemplo, consideram os animais de caça da floresta iguais a eles mesmo, pois sabem que ambos já foram humanos um dia, quando eram juntos parte da primeira humanidade, dos ancestrais animais (KOPENAWA; ALBERT, 2016, p. 117). Então, os xapiri convivem com os animais de caça e os reconhecem enquanto também humanos, assim como os xamãs reconhecem ambos enquanto humanos (KOPENAWA; ALBERT, 2016, p. 118). Os xapiri, então como os xamãs, também sabem que os animais que hoje vivem na floresta são em parte ainda humanos (VALENTIM, 2018, p. 194), pois são uma transformação dos primeiros seres. "Os animais também são humanos" (KOPENAWA; ALBERT, 2016 p. 206), diz o xamã, o que talvez seja melhor compreendido pensando-se que eles são também em parte humanos (VALENTIM, 2018, p. 194).

Então, pensando a tríade que forma a base cosmológica de Kopenawa (KOPENAWA, 2016, p. 616), primeiro tem-se os yãnomami thëpë, os "seres humanos", que de uma forma geral contrastam com outras duas categorias. Essas, por sua vez, são os yaropë, os animais de caça, que, porém, são também humanos, e os yai thëpë, os seres invisíveis, nos quais os xapiri estão inclusos, que também são parecidos com os humanos; segundo o xamã (KOPENAWA; ALBERT, 2016. p. 111). Essas informações podem levar, em uma leitura rápida, a uma estabilização humana do cosmos, segundo as palavras de Kopenawa. Mas o xamã diz mais coisas sobre esses espíritos. A questão é que, além de aproximar esses agentes dos humanos, o xamã também diz que os napë chamam os xapiri de espíritos, mas eles são outros, pois não são completamente iguais aos humanos, não têm as mesmas características (KOPENAWA; ALBERT, 2016, p. 111). Se Kopenawa (2016) indica uma antropomorfia de tudo em um primeiro instante, essa antropomorfia vem sempre acompanhada de uma teriomorfia (VALENTIM, 2018, p. 195), de uma transformação da humanidade em besta, de um excesso monstruoso do sobrenatural: em suma, os xapiri são humanos, mas também são outros, então eles são humanos que sempre estão relacionados a um fora não-humano (VIVEIROS DE CASTRO, 2006, p. 326)

Primeiro, é importante ressaltar que os xapiri apresentam diferenças corporais em relação aos humanos, como órgãos genitais pequenos, mãos com menos dedos e são muito pequenos (minúsculos) (KOPENAWA; ALBERT, 2016, p. 111). Essas são características aquém das humanas "normais", são como traços de forma diminuta, traços anormais. Os xapiri são também imortais, e em vez de andar pela floresta, eles podem contemplá-la voando em alta velocidade, lembrando luzes cintilantes dispersas pelo ar. São ainda muito cheirosos e "a brisa de seu voo espalha perfume tão intenso quanto dos perfumes dos brancos" (KOPENAWA; ALBERT, 2016, p. 112)9. Além disso, são muitos, são infinitos, e mesmo todos os brancos juntos ficam em pouca quantidade perto deles (KOPENAWA; ALBERT, 2016, p. 118). Possuem, assim, também características para além do humano "normal", algo como superpoderes. Os 
espíritos são seres estranhamente humanos, são híbridos, mesclados, pois apresentam características humanas, mas sempre acompanhadas de uma deformação, seja para mais ou para menos.

Os xapiri são marcados pelo "excesso, monstruosidade ou não-humanidade (sobrenaturalidade)" (KOPENAWA; ALBERT, 2016, p. 225). Como Viveiros de Castro (2006) argumenta, o que determina os espíritos "é a sua capacidade intrínseca de ser outra coisa" (VIVEIROS DE CASTRO, 2006, p. 324), ou seja, eles sempre são usados nas narrações xamânicas para depois serem trocados, substituídos, transformados. Estão assim sempre inclinados a serem outra coisa, inclinados para além da própria humanidade. O que marca os espíritos é a "auto diferença” (VIVEIROS DE CASTRO, 2006, p. 324), ou seja, sua capacidade de "(trans-) figuração" (VALENTIM, 2018, p. 221). Pode-se pensar neles enquanto um "potencial de alteração" (LEITE, 2010, p. 220). Os xapiri são seres prontos para assumir outra forma, são seres sempre na eminência de se tornarem outro. Pode se pensar junto com Valentim (2018), que diz que o xamã ao dizer que os xapiri são parecidos com os humanos, mas também são outros, diz isso no sentido de que os espíritos são humanos e mais algo além dos humanos, são como extra-humanos(VALENTIM, 2018, p, 200).

\section{A HUMANIDADE FINGIDA}

Embora sejamos humanos, eles (animais de caça) nos chamam pelo mesmo nome que dão a si mesmos. Por isso acho que nosso interior é igual ao da caça, mesmo se atribuímos a nós mesmos o nome de humanos, fingindo sê-lo (KOPENAWA; ALBERT, 2016, p. 473).

Nestas palavras de Kopenawa, a humanidade é caracterizada enquanto um fingimento, enquanto uma aparência exterior que dissimula a interioridade. Como já foi expresso neste artigo, os xapiri são sempre levados a analogias de identificação com humanos, pois eles são como os humanos, mas, em outros momentos, o xamã destaca que eles não são exatamente como os humanos, pois são outros também, carregados de uma anomalia, de uma irregularidade, de algo incomum para o humano "normal". Agora ele soma à situação uma humanidade que aparece como um disfarce, enquanto dissimulação. Um modo de encarar esta situação é pensar na chave de um (interior)extra-humano/(exterior)corpo-humano-ou-outro, e não na chave (interior)humano/(exterior)corpo-humano. Ao invés de um interior humano invisível, junto a um corpo visível e exposto, com a soma que tudo que tem o interior humano tem o corpo também humano, o que se tem no xamanismo é um interior de forma meio humana e meio não-humana (extra-humana/além-humana), que é supervisível para os xamãs e invisível para os não xamãs, e um exterior visível para qualquer um, que pode ser um corpo humano ou mesmo um outro corpo não humano.

Pode-se então pensar que o lado humano interno é realmente só um lado, pois o outro lado desse interior é para além da humanidade. Sendo assim, a antropomorfia "seria apenas parcial, ela constitui apenas um dos lados da moeda" (VALENTIM, 2018, p. 194), e deste modo nada é humano completamente. No jogo de posições do xamanismo, "a antropomorfia de uns corresponde à teriomorfia de outros (e vice-versa)" (VALENTIM, 2018, p. 194). Tudo então é parecido com o humano, mas tudo também mantém uma vida escondida não-humana (VALENTIM, 2018, p. 194). E também, como já analisado, a alta intensidade que a humanidade ameríndia apresenta sempre se dá em mão dupla, pois enquanto alguém se torna humano, o outro deixa de ser, e assim a humanidade nunca é ocupada simultaneamente por todos. Se no xamanismo 
tudo é humano, nem todos são completamente humanos, e também nem todos são ao mesmo tempo humanos.

Para o moderno o que é comum a tudo e a todos que existem é um corpo "natural" exterior, visto por todos, ou seja, tudo/todos têm um corpo, enquanto uma alma interior é o que diferencia os humanos do resto, já que os humanos apresentam excepcionalmente uma interioridade. Para o xamanismo, por sua vez, o que é comum a todos, sejam eles humanos ou não, é uma essência (além) extra-humana - espiritual (utupë) - encontrada em todos que existem, nem totalmente humana, nem totalmente não-humana, algo antropo-terio-mórfico (VALENTIM, 2018, p. 195), enquanto a humanidade seria apenas uma aparência corporal que varia, e que pode ser trocada de acordo com as relações e encontros que se estabelecem com os outros seres extra-humanos. O conceito de antropo-terio-morfia, criado pelo filósofo brasileiro, é importante para que a instabilidade enquanto característica marcante da humanidade xamânica seja transportada para o interior do conceito de antropomorfia, assim implodindo o antropocentrismo que o termo carrega em seu próprio nome.

O conceito de antro-terio-morfismo é apresentado no livro Extramundanidade e sobrenatureza, no qual é realizado uma longa discussão para pensar os limites do antropomorfismo. Mais exatamente, discute-se o antropomorfismo proposto por Viveiros de Castro no perspectivismo, o "corolário (etno)epistemológico do animismo" (VIVEIROS DE CASTRO, 1996, p. 122), que já foi apresentado neste artigo. As questões de Valentim (2018) incidem no antropocentrismo que a palavra antropomorfismo carrega consigo, mais diretamente sobre o anthropos do antropo-morfismo. Como já foi exposto, o perspectivismo aponta para uma instabilidade humana em alta temperatura, e para o filósofo, $o$ conceito antropomorfismo não leva em conta esse ponto, ou melhor, não leva até as últimas consequências a instabilidade humana. A argumentação do filósofo aponta que, caso isso ocorresse, exigiria uma transformação do próprio nome do conceito. A hipótese do filósofo propõe que se transporte para o interior do conceito antropomorfia a instabilidade que alguns argumentos do próprio perspectivismo indicam, então em vez de antropomorfismo, se tem um antropo-terio-morfismo ${ }^{10}$. Valentim (2018) leva o perspectivismo para além do próprio perspectivismo, e assim o transforma em uma espécie de extraperspectivismo,e assim, na teriomorfia, a instabilidade do humano proposta pelo xamanismo alcança seu ponto mais intenso.

\section{CONSIDERAÇÕES FINAIS}

A questão que pulsou neste artigo envolveu os problemas que são criados quando a separação entre os humanos e aquilo que está para além dos humanos é provocada, tirada do conforto, tirada do ponto ideal moderno. A expansão do restrito círculo humano para coisas que estão predeterminadas enquanto fora dos humanos leva a um terreno íngreme e escorregadio, que apresenta avalanches difíceis de se transpor, e no qual é fácil cair em contradições, e a antropologia — já em seu nome - revela que parte desta problemática é essencial para seu futuro.

Este artigo focou em diferentes respostas, de diferentes autores, para os problemas que se abrem quando se pensa nas diferenças entre aqueles e aquilo, entre os quê(s) e os quem(s), e todas estas respostas foram sempre escritas com as palavras de Kopenawa logo à espreita. Se alguém mais pensa — quem são eles? Dizer que esse novo pensamento é igual ao dos humanos não parece muito criativo, para dizer o mínimo. Uma saída está em repensar quem são outros e, por consequência, em quem somos nós (humanos), e não em colar o 
que estava dentro do círculo humano para o lado de fora. Como visto, quanto mais se amplia a esfera humana, mais difícil fica de pensar o que poderia ser um mundo todo humano, já que quando expandida em seu limite, a diferença desvanece nas mãos daquele que a controla, pois se todos pensam, já não podemos diferenciar o todo do tudo.

A intenção durante todo o artigo foi a de construir pontes entre as palavras do xamã e as palavras dos napë, para que, assim, a vontade de Kopenawa de que os brancos escutem as vozes dos espíritos da floresta, dos xapiri, fosse ao menos impulsionada. Ao invés de buscar os textos antigos da Antropologia/Filosofia, a minha busca foi a de me manter próximo dos últimos textos publicados sobre o assunto, o que envolveu a tríade de antropólogos, Philippe Descola, Viveiros de Castro e Eduardo Kohn, e também principalmente dois filósofos brasileiros Hilan Bensusan e Marco Valentim. Este artigo se formou basicamente de um mosaico dos argumentos destes diferentes autores, que deram fôlego para que a floresta xamânica fosse enfrentada e conhecida.

Quem é o quem? E o que é o quê? São perguntas que a floresta impõe a quem dá uma volta por ela. Se quase tudo, ou mesmo tudo ali pensa, é inteligente, tem alma, agência, consciência, tem uma utupë, uma volta pela floresta causa uma vertigem ao pensamento dos brancos que se acostumou a ver os humanos sozinhos no mundo, como aqueles únicos que pensam. A pergunta que perturbou este artigo foi aquela que nunca deixou os humanos se sentirem especiais, sozinhos, pois a floresta é muito mais que um cidadão da cidade pode imaginar. O xamanismo, neste sentido, é um atalho para explosão da parede da soberania humana imposta pela modernidade que rebaixa tudo o que não é humano para o porão da casa.

Como Viveiros de Castro provoca no posfácio de Extramundanidade e sobrenatureza, este livro é a contribuição mais original que a filosofia brasileira já deu, e grande parte desta contribuição se deve à força das palavras do xamã Davi Kopenawa, que serviu para o filósofo brasileiro como um dia Sócrates serviu para Platão. A influência de Kopenawa nos pensadores ocidentais acaba de começar, e o crescimento da leitura do livro entre os brancos se encontra em crescimento exponencial, o que é um bom sinal. Se os brancos não conseguirem levar a sério os insigths do xamã, logo a obra xamânico-antropológica se tornará mais um artigo exótico na prateleira dos brancos, uma simples "coisa", e então permanecerá sempre citada enquanto um estranho artefato não articulado às ideias da Antropologia. Mas, caso contrário, se levados a sério, o livro será decisivo para a Antropologia enquanto um exemplo raro de um encontro bom entre um antropólogo e um xamã, com o poder de desviar a modernidade para um futuro que promete ser atordoante.

\section{NOTAS}

1 "Yanomami" é uma simplificação da palavra yanõmami tëpë, que significa "humanos", e é utilizado por algumas sociedades ameríndias, inclusive por parte dos Yanomami.

${ }^{2}$ A obra $A$ queda do céu teve sua primeira transcrição para uma língua ocidental na França, no ano de 2010. O trabalho de construção a "quatro mãos" da obra se baseou em um "pacto etnográfico" (KOPENAWA; ALBERT, 2016, p. 520), no qual o antropólogo serviu como um "intermediário, a favor deles, na comunicação entre os dois mundos" (KOPENAWA; ALBERT, 2016, p. 521). O trabalho de transcrição e tradução das narrações do xamã durou quase vinte anos para ser realizado e seguiu o imperativo de "fazer justiça de modo escrupuloso à imaginação conceitual” (KOPENAWA; ALBERT, 2016 p. 520) do xamã.

${ }^{3}$ A palavra napë é utilizada pelo xamã para se referir aos brancos, aos modernos, aos invasores da floresta (KOPENAWA; ALBERT, 2016, p. 610).

${ }^{4}$ As questões que envolvem o antropomorfismo atravessam a antropologia desde seu 
início até os dias atuais. Maiores detalhes podem ser encontrados na coletânea de texto The handbook of contemporary animism.

${ }^{5}$ Nos debates atuais, a definição da palavra agência se aproxima à definição de um indivíduo consciente, um agente consciente, ou seja, como aquilo que pode ser a fonte de uma ação, a origem de uma ação. "Atribuir agência a algo seria, nesse sentido, atribuir mente ou intuição, não importa se a pessoas ou coisas" (SZTUTMAN, 2005, p. 75).

${ }^{6}$ Esses são dois filósofos brasileiros, que não por acaso, lançaram livros nos últimos anos sobre o animismo/xamanismo e tudo o que o tema envolve, e também são filósofos que acompanham de perto o desenvolvimento da Antropologia. Iremos expor algumas de suas ideias que têm influência direta nos debates atuais da antropologia.

${ }^{7}$ Aqui me refiro à ideia "Antropoceno" que foi proposta pelo biólogo Eugene F. Stoemer e pelo químico Paul Crutzen no ano de 2000, enquanto um novo período geológico que aponta para a catástrofe ambiental.

${ }^{8} \mathrm{Na}$ mitologia yanomami são dadas três humanidades sucessivas. A primeira humanidade se transformou na caça dos dias de hoje, uma segunda humanidade foi extinta devido a uma chuva cataclísmica e a terceira é a humanidade a qual os Yanomami de hoje pertencem (LEITE, 2010, p. 41)

${ }^{9}$ Temos o interessante filme Xapiri, dirigido por Leandro Lima, Gisele Motta, Laymert Garcia, Stella Senta e Bruce Albert, no qual se busca mostrar as visões que os xamãs alcançam após alterarem a consciência através da yãkoana.

${ }^{10}$ Como Valentim (2018) coloca, o antropo-terio-morfismo é resultado das consequências dos argumentos do perspectivismo; é como se o perspectivismo fosse antropomorfista só na aparência, mas na verdade ele já é antro-terio-morfista em sua essência.

\section{REFERÊNCIAS}

ALBERT, Bruce. O ouro canibal e a queda do céu: uma crítica xamânica da economia política da natureza. In: ALBERT, Bruce; RAMOS, Alcida (Eds.). Pacificando o branco: cosmologias do contato no Norte-Amazônico. São Paulo: IMESP/IRD/Ed. UNESP, p. 239-274, 2002.

BENSUSAN, Hilan. Linhas de animismo futuro. Brasília: IEB Mil Folhas, 2017. CALAVIA SÁEZ, Oscar. O nome e o tempo do Yaminawa: etnografia história dos Yaminawa do rio Acre. São Paulo: Editora UNESP, 2006.

CAMPOS, Raquel; DAHER, Andrea. A antropologia da natureza de Philippe Descola. Topoi, Rio de Janeiro, v. 14, n. 27, p. 495-517, dez. 2013.

CHAKRABARTY, Dipesh. O clima da história: quatro teses. Sopro, São Paulo, n. 91, p. 1-22, jul. 2013.

DANOWSKI, Déborah; VIVEIROS DE CASTRO, Eduardo. Há um mundo por vir? Ensaio sobre os medos e os fins. Florianópolis: Cultura e Barbárie, 2014.

DESCOLA, Philippe. As lanças do crepúsculo: Relações Jivaro na Alta Amazônia. São Paulo: Cosac Naify, 2006.

. Beyond Nature and Culture. Chicago: The University of Chicago, $2013 \mathrm{a}$.

. A antropologia da natureza de Philippe Descola. [Entrevista concedida à] Andréa Daher, Rio de Janeiro, Topoi, v. 14, n. 27, p. 495-517, dez. 2013b.

HABERMAS, Jürgen. A constelação pós-nacional: ensaios políticos. São Paulo: Littera-Mundi, 2001.

HOLBRAAD, Martin; PEDERSEN, Morten Axel. The ontological turn: an anthropological exposition. Cambridge: Cambridge University press, 2017.

LATOUR, Bruno. Jamais fomos modernos: ensaio de antropologia simétrica. 3. ed. São Paulo: Editora 34, 2013.

LEITE, Tainah Víctor. Pessoa e humanidade nas etnografias Yanomami. Dissertação. (Programa de Pós-Graduação em Antropologia Social) Departamento de Ciências Sociais, Universidade Federal do Rio de Janeiro, Rio de Janeiro, 2010. 
LÉVI-STRAUSS, Claude. Antropologia estrutural dois. São Paulo: Cosac Naify, 2013.

LIMA, Tânia Stolze. O dois e seu múltiplo: reflexões sobre o perspectivismo em uma cosmologia tupi. Mana, v. 2, n. 2, p. 21-47, out. 1996.

KOHN, Eduardo. How forests think: toward an Anthropology beyond the human. Los Angeles/London: University of California, 2013.

KOPENAWA, Davi; ALBERT, Bruce. A queda do céu: palavras de um xamã yanomami. $1^{a}$ reimpressão. São Paulo: Companhia das letras, 2016.

MORRISON, Keneth M. Animism and a proposal for a post-Cartesian immediacy. In: HARVEY, Graham. (Eds.). The handbook of contemporary animism. New York: Routledge, 2014.

SÁ JUNIOR, Luiz César. Philippe Descola e a virada ontológica na antropologia. ILHA, v. 16, n. 2, p. 7-36, ago./dez. 2014.

STENGERS, Isabelle. The cosmopolitical proposal. In: LATOUR, Bruno; WEIBEL, Peter. (Eds.). Making thing public: atmospheres of democracy. Cambridge: MIT Press, p. 994-1003, 2005.

. No tempo das catástrofes. São Paulo: Cosac Naify, 2015.

SZTUTMAN, Renato. O profeta e o principal: A ação política ameríndia e seus personagens. Tese. (Programa de Pós-Graduação em Antropologia Social) Departamento em Ciências Sociais, Universidade de São Paulo, São Paulo, 2005.

VALENTIM. Marco Antônio. Extramundanidade e sobrenatureza: ensaios de ontologia infundamental. Florianópolis: Cultura e Barbárie, 2018.

VIVEIROS DE CASTRO, Eduardo. Os Pronomes Cosmológicos e o perspectivismo ameríndio. Mana, v. 2, n. 2, p. 115-144, out. 1996.

. A inconstância da alma selvagem. São Paulo: Cosac Naify, 2002.

. A floresta de cristais: notas sobre a ontologia dos espíritos amazônicos.

Cadernos de campo, v. 14/15, n. 14/15, p. 319-338, 2006.

. Metafísicas canibais: Elementos para uma antropologia pós-estrutural.

São Paulo: Cosac Naify, 2015a.

. Conferência de Encerramento. In: Variações do corpo selvagem: Edu-

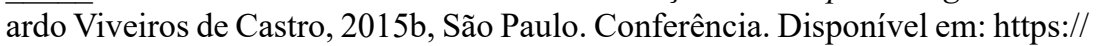
www.youtube.com/watch?v=neWz33m6dgI. Acesso em: 10 mar. 2019. 